\title{
EXTRAÇÃO DA FRAÇÃO HEMICELULÓSICA DE CAVACOS DE MADEIRA VISANDO SUA APLICAÇÃO EM BIORREFINARIAS
}

\author{
C.M. MORGANTE ${ }^{1}$, N. BONTURI ${ }^{1}$ e E.A MIRANDA ${ }^{1}$ \\ ${ }^{1}$ Universidade Estadual de Campinas, Faculdade de Engenharia Química \\ E-mail para contato: carolina.morgante@gmail.com; everson@feq.unicamp.br.
}

\begin{abstract}
RESUMO - A biomassa lenhosa é uma fonte importante de celulose e hemicelulose, pois está disponível de maneira sustentável no país. Na produção de celulose e papel, a fração hemicelulósica é usada para geração de vapor e energia, porém, o calor específico desse açúcar é baixo, o que torna o seu uso na queima pouco eficiente. A extração da hemicelulose dos cavacos de madeira antes da polpação de forma com que a hemicelulose possa ser hidrolisada e usada como fonte de carbono para produção de produtos com maior valor agregado (tais como etanol, ácido succínico, xilitol e single cell oil) é uma opção melhor de aproveitamento deste componente. O presente trabalho tem como objetivo estudar a extração da hemicelulose a partir de cavacos de Eucalyptus urograndis visando sua aplicação como fonte de carbono para processos fermentativos microbiano. As variáveis de extração estudadas foram o líquido de extração (água, soluções aquosas de ácido sulfúrico e hidróxido de sódio e licor branco), a proporção sólido: líquido de 1:3, 1:6 e 1:9 e o tempo de extração de 60, 90 e $120 \mathrm{~min}$. Obteve-se uma baixa concentração do açúcar de interesse nos extratos, sendo que o maior rendimento de xilose foi $0,4 \%$ na extração com água como líquido de extração nas proporções sólido:líquido de 1:3 e 1:9 e na condição usando licor branco com álcali efetivo de 7\% na proporção 1:6.
\end{abstract}

\section{INTRODUÇÃO}

O conceito de biorrefinaria define a utilização de biomassa lignocelulósica como matéria prima para gerar uma variedade de produtos de interesse econômico (Hodge et al., 2009) e uma das formas em que tem sido desenvolvida é através da plataforma bioquímica, que faz uso de processos de extração, separação e conversão de biomassa em produtos diversos por fermentação (Mendes et al., 2009). A biomassa lenhosa é um produto agroindustrial fonte de celulose e hemicelulose, e está disponível de maneira sustentável e em grandes quantidades no Brasil (BRACELPA, 2011), que é atualmente o quarto produtor mundial de celulose, sendo que $44 \%$ dessa produção é oriunda de plantações de eucalipto (BRACELPA, 2011). De acordo com Magaton et al. (2006), o Eucalyptus urograndis é a 


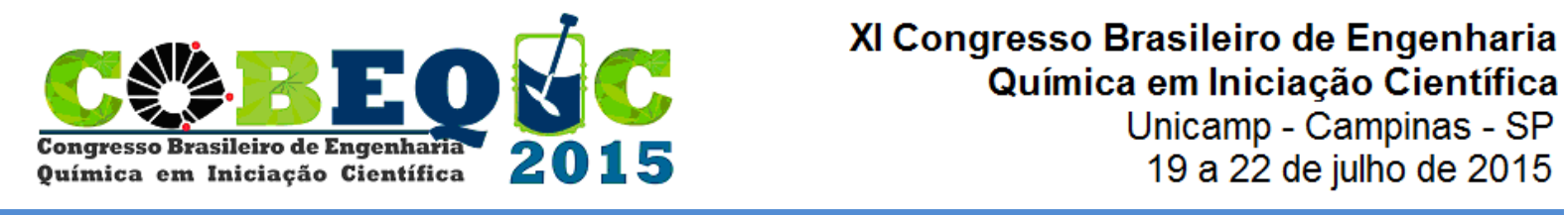

espécie mais utilizada pela indústria papeleira do Brasil e têm composição média de 19,4\% de hemicelulose, $10,3 \%$ de xilana, $52,0 \%$ de celulose e $71,4 \%$ de açúcares totais.

O processo mais utilizado para a obtenção de celulose na indústria papeleira é o processo Kraft (Engelberth et al., 2012), em que os cavacos são aquecidos a $170^{\circ} \mathrm{C}$ em um reator pressurizado e digeridos por uma mistura de hidróxido de sódio e sulfeto de sódio em água, chamada de licor branco, resultando em polpa de celulose não branqueada, que segue na produção de papel e em licor negro, mistura de lignina, hemicelulose e compostos inorgânicos que é normalmente queimado para geração de vapor e energia (Vila et al., 2011). Embora a lignina tenha alto calor específico $(27,0 \mathrm{MJ} / \mathrm{kg})$, o calor específico da hemicelulose é cerca da metade, o que faz com que a contribuição da hemicelulose ao processo de queima não seja eficiente (Vila et al., 2011). Desta maneira, sugere-se a extração seletiva da hemicelulose antes da etapa de polpação para seu uso, na forma monomérica após hidrólise, como substrato para processos microbiológicos visando a obtenção produtos de maior valor agregado (Engelberth et al., 2012).

Essa extração antes da polpação pode ser feita com água quente (auto-hidrólise) ou em condições ácidas ou básicas. Pelo levantamento bibliográfico feito observa-se que a maioria das publicações científicas listadas usa a auto-hidrólise, mas há também relatos de extração usando hidróxido de sódio (Huang et al., 2010), mistura de hidróxido de sódio, carbonato de sódio e sulfeto de sódio (Helmerius et al., 2010) e ácido sulfúrico (Canettieri et al., 2005). As temperaturas testadas variaram de $90^{\circ} \mathrm{C}$ por $240 \mathrm{~min}$ (Huang et al., 2010) a $200^{\circ} \mathrm{C}$ por $40 \mathrm{~min}$ (Helmerius et al., 2010) e as proporções sólido:líquido (massa de cavacos de madeira em gramas para massa de solução de extração em gramas) variam de 1:3 a 1:9.

Não foi encontrado na literatura estudos de extração específica de hemicelulose de madeiras visando a utilização dos extratos hemicelulósicos para a produção de single cell oil (SCO), permitindo assim, não só um melhor aproveitamento de todas as correntes de produtos (celulose, lignina, hemicelulose), mas também agregando produtos de maior valor agregado ao portfólio das indústrias de papel e celulose. O presente projeto de iniciação científica é parte de um esforço em se preencher essa lacuna técnico-científica, integrando um projeto de produção de SCO a partir de leveduras oleaginosas cultivadas em hidrolisados hemicelulósicos.

\section{MÉTODOS}

\subsection{Preparo dos cavacos de madeira}

Os cavacos de eucalipto da espécie E. urograndis, gentilmente cedidos pela Fibria Celulose S.A. (Jacareí, São Paulo), foram cortados manualmente em tamanhos de cerca de $0,5 \times 4,0 \times 4,0 \mathrm{~cm}$. 


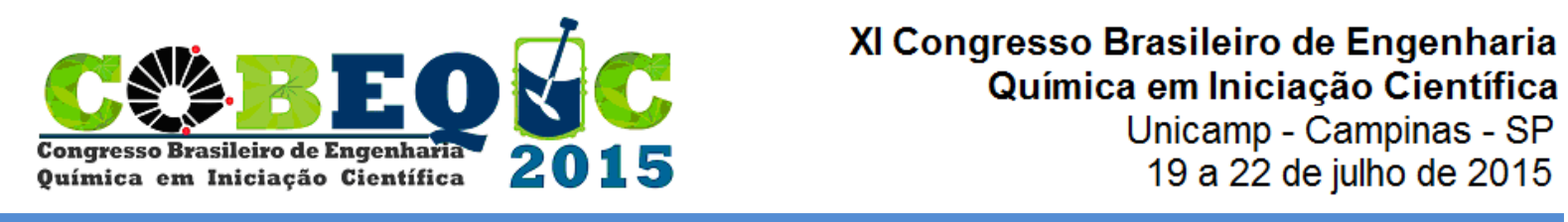

\subsection{Determinação do teor de umidade dos cavacos}

A umidade dos cavacos de eucalipto foi determinada gravimetricamente por secagem em estufa a $105^{\circ} \mathrm{C}$ até obtenção de massa constante (Sluiter et al., 2008). Por se tratar de uma sequência de experimento preliminares, a determinação da umidade foi feita apenas em duplicata.

\subsection{Estudos de extração de hemicelulose}

Os cavacos de madeira de eucalipto previamente pesados foram acondicionados em vidraria autoclavável nas proporções sólido:líquido $(\mathrm{m} / \mathrm{m})$ de 1:3, 1:6 e 1:9 com as fases líquidas de extração. A extração foi realizada em autoclave vertical de capacidade $75 \mathrm{~L}$ de (modelo CS, Prismatec, Brasil), e apenas à $120^{\circ} \mathrm{C}$ por uma limitação do equipamento.

\subsection{Determinação de açúcares redutores}

Como técnica de avaliação rápida para screening de condições de pré-extração promissoras, utilizou-se o método de ácido dinitrosalicílico (DNS) proposto por Miller (1959) para a determinação de açúcares redutores.

\subsection{Hidrólise ácida}

A hidrólise ácida dos extratos foi realizada conforme descrito por Sluiter et al. (2006), s uma concentração de ácido sulfúrico de $4 \%$ por 60 min a $120^{\circ} \mathrm{C}$, seguida do ajuste do $\mathrm{pH}$ para 5,0 utilizando hidróxido de cálcio (sólido em pó).

\subsection{Quantificação de açúcares monoméricos, ácido acético, hidroxi-metil- furfural e furfural}

As quantificações de glicose e xilose e dos inibidores ácido acético, HMF e furfural dos hidrolisados foram realizadas através de CLAE, utilizando coluna Aminex 87H (Biorad, EUA). O volume de injeção foi de $70 \mu \mathrm{L}$ e o forno e detector foram mantidos a $65^{\circ} \mathrm{C}$. Ácido sulfúrico $5 \mathrm{mmol} / \mathrm{L}$ foi usado como fase móvel a uma vazão de $0,6 \mathrm{~mL} / \mathrm{min}$.

\section{RESULTADOS E DISCUSSÕES}

\subsection{Teor de umidade dos cavacos}

A umidade dos cavacos de E. urograndis foi determinada como sendo $18,7 \pm 1,1 \%$. Esse valor foi considerado nos cálculos para determinação das proporções sólido: líquido (massa de madeira:massa de líquido de extração) na etapa de extração de hemicelulose.

\subsection{Extração com água}


Para determinação o melhor tempo de extração realizou-se a extração de hemicelulose dos cavacos de madeira utilizando-se água como líquido de extração em três diferentes proporções sólido:líquido (1:3, 1:6 e 1:9) por 60, 90 e $120 \mathrm{~min}$, seguida pela hidrólise ácida e ajuste de $\mathrm{pH}$. Para uma análise preliminar, quantificou-se os açúcares redutores dos hidrolisados. A extração de 60 min obteve concentração (massa de açúcar redutor/volume de extrato hidrolisado) de 1,6 g/L na proporção 1:3 e 1,4 g/L nas proporções 1:6 e 1:9. A de 90 min obteve $2,1 \mathrm{~g} / \mathrm{L}, 1,3 \mathrm{~g} / \mathrm{L}$ e 1,2 g/L nas proporções 1:3, 1:6 e 1:9. Já a extração de 120 min apresentou as maiores concentrações independente das proporções testadas, obtendo concentrações de 2,8 g/L na proporção 1:3, 1,8 g/L na1:6 e 3,1 g/L na 1:9 e por isso adotou-se esse tempo para as próximas extrações.

Os extratos obtidos na extração durante 120 min foram analisados por CLAE para quantificação de açúcares monoméricos, ácido acético, hidroxi-metil-furfural (HMF) e furfural. Não foram identificadas concentrações de HMF ou de furfural nos extratos. Todas as proporções testadas apresentaram concentração de glicose de $0,7 \mathrm{~g} / \mathrm{L}$. A concentração de xilose também variou pouco, sendo de $0,6 \mathrm{~g} / \mathrm{L}$ para as proporções $1: 3$ e $1: 9$ e de $0,5 \mathrm{~g} / \mathrm{L}$ para a proporção 1:6. Em termos de rendimento, temos que o maior rendimento de xilose da extração com água foi de $0,40 \%$ (em termos de massa inicial de madeira). A literatura valores de rendimento de xilana variando de 2,7 a $10,9 \%$ em extrações com água, valores bastante discrepantes com os aqui obtidos.

\subsection{Extração em solução ácida}

A extração realizada foi feita com solução de ácido sulfúrico $5 \mathrm{mmol} / \mathrm{L}$ por $120 \mathrm{~min}$ a $120{ }^{\circ} \mathrm{C}$ e realizou-se a quantificação dos açúcares por CLAE. HMF e furfural não foram detectados nos extratos. A concentração de glicose foi de $0,5 \mathrm{~g} / \mathrm{L}, 0,2 \mathrm{~g} / \mathrm{L}$ e $0,3 \mathrm{~g} / \mathrm{L}$ para extrações realizadas com proporção sólido:líquido 1:3, 1:6 e 1:9, respectivamente. A concentração de xilose foi de $0,7 \mathrm{~g} / \mathrm{L}, 0,4 \mathrm{~g} / \mathrm{L}$ e $0,3 \mathrm{~g} / \mathrm{L}$ para as proporções 1:3, 1:6 e 1:9, respectivamente A maior concentração de ácido acética foi encontrada na extração feita com proporção 1:3 (0,3 g/L) e a menor na extração 1:9 (0,1 g/L). Portanto, o maior rendimento de xilose da extração utilizando solução ácida como líquido de extração foi de $0,13 \%$ (em termos de massa inicial de madeira) no caso em que a proporção massa de madeira:massa de líquido de extração foi de 1:3.

\subsection{Extração em solução básica}

A extração realizada foi feita com solução de hidróxido de sódio $1,5 \mathrm{~mol} / \mathrm{L}$ por 120 min a $120^{\circ} \mathrm{C}$. Novamente, HMF e furfural não foram detectados nos extratos. A concentração de glicose foi de $0,5 \mathrm{~g} / \mathrm{L}, 0,2 \mathrm{~g} / \mathrm{L}$ e $0,3 \mathrm{~g} / \mathrm{L}$ para extração feita com proporção $1: 3,1: 6$ e 1:9 respectivamente. A concentração de xilose foi de $0,7 \mathrm{~g} / \mathrm{L}, 0,4 \mathrm{~g} / \mathrm{L} \mathrm{e} 0,3 \mathrm{~g} / \mathrm{L}$ para as proporções 1:3, 1:6 e 1:9, respectivamente. A maior concentração de ácido acético foi encontrada na extração feita com proporção 1:3 $(0,3 \mathrm{~g} / \mathrm{L})$ e a menor na extração $1: 9(0,1 \mathrm{~g} / \mathrm{L})$. HMF, furfural e glicose não foram detectados. A maior concentração de xilose foi na extração de proporção sólido:líquido $1: 3(0,2 \mathrm{~g} / \mathrm{L})$. No entanto, as amostras apresentaram altas 


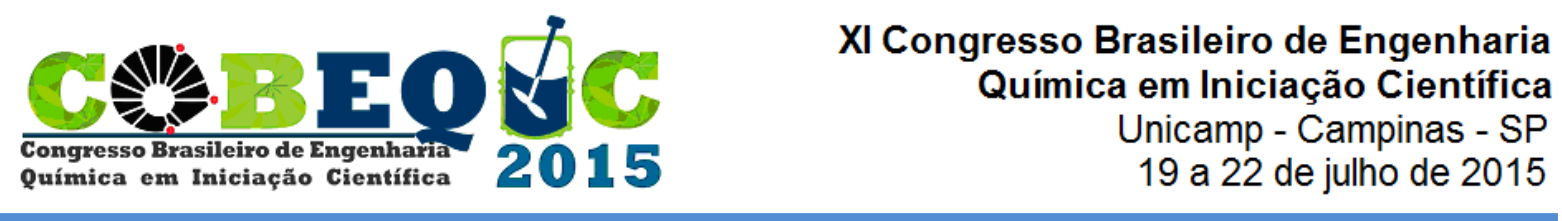

concentrações de ácido acético, chegando a 5,5 g/L na proporção 1:3. Dessa forma, o maior rendimento de xilose da extração com solução básica como líquido de extração foi de $0,02 \%$ (em termos de massa inicial de madeira) no caso em que a proporção massa de madeira:massa de líquido de extração foi de 1:3, valor muito inferior ao descrito por Huang et al., 2010 (cujo rendimento de xilana foi de $14 \%$ ).

\subsection{Extração com licor branco}

No experimento realizado testou-se o licor branco com 3\% e 7\% de álcali efetivo (EA). Após a hidrólise ácida dos extratos, realizou-se a quantificação de açúcares monoméricos, ácido acético, HMF e furfural de acordo com o descrito no item 2.6. HMF e furfural não foram detectados. A maior concentração de glicose encontrada na extração feita com solução a $3 \%$ EA foi de $0,3 \mathrm{~g} / \mathrm{L}$ na proporção $1: 6$, mesma condição com maior concentração de xilose $(0,3 \mathrm{~g} / \mathrm{L})$. Portanto, o maior rendimento de xilose dessa extração foi de 0,13\% (em termos de massa inicial de madeira) no caso em que a proporção sólido:líquido de extração foi de 1:6. A extração com solução 7\% EA apresentou a maior concentração de glicose $(0,1 \mathrm{~g} / \mathrm{L})$ na extração feita com proporção sólido:líquido $1: 6$, que também apresentou maior concentração de xilose $(0,6 \mathrm{~g} / \mathrm{L})$. Helmerius et al. (2010) também utilizaram licor branco na extração de hemicelulose de Betula pendula, obtendo rendimento de $14 \%$ de xilana, valor muito superior à porcentagem de xilose extraída nesse ensaio.

\section{CONCLUSÕES}

Neste estudo observou-se a influência que o tempo da extração tem sobre o rendimento de xilose. Foram testadas extrações com duração de 60, 90 e 120 min com a mesma temperatura $\left(120^{\circ} \mathrm{C}\right)$ e observou-se maior rendimento do açúcar de interesse (xilose) no procedimento de maior duração. $\mathrm{O}$ maior rendimento de xilose dos experimentos realizados foi de apenas $0,4 \%$ (nas condições que utilizaram água como líquido de extração na proporção $1: 3$ e 1:9 e na condição usando licor branco com álcali efetivo de $7 \%$ na proporção 1:6), no entanto trata-se de uma concentração baixa que impossibilita sua aplicação técnica. Visando melhorar a extração de hemicelulose dos cavacos de Eucalyptus urograndis, os próximos experimentos serão feitos com cavacos de madeira com tamanho reduzido após moagem em moinhos de faca e utilizando uma unidade de extração supercrítica (Egydio et al., 2010) visando utilizar valores maiores de pressão (100-1000 bar) e novas faixas de temperatura $\left(130-150^{\circ} \mathrm{C}\right)$.

\section{REFERÊNCIAS}

BRACELPA. Associação Brasileira de Celulose e Papel. 2011. Disponível em: < http://www.bracelpa.org.br/pt/ >. Acesso em: 15/09/2014.

Canettieri, E.V; Rocha, G.J.M.; Carvalho, J.A.; Silva, J.B.A., Optimization of acid hydrolysis from the hemicellulosic fraction of Eucalyptus grandis residue using response surface methodology, Bioresource Technology, v.98, p.422-428, 2005. 
Engelberth, A.S.; Walsum, G.P., Adding Value to the Integrated Forest Biorefinery with Coproducts from Hemicellulose-Rich Pre-Pulping Extract. In: Bergeron, C.; Carrier, D.J.; Ramaswamy, S., Biorefinery Co-Products: Phytochemicals, Primary Metabolites and Value-Added Biomass Processing, John Wiley \& Sons, 2012, p. 287-310.

Helmerius, J.; Walter, J.V.; Rova, U.; Berglund, K.A.; Hodge, D.B., Impact of hemicellulose pre-extraction for bioconversion on birch Kraft, Bioresource Technology, v. 101, p. 5996-6005, 2010.

Hodge, D.B.; Andersson, C.; Berglund, K.A.; Rova, U., Detoxification Requirements for Bioconversion of Softwood Dilute Acid Hydrolyzates to Succinic Acid, Enzyme and Microbial Technology, v. 44, p. 309-316, 2009.

Huang, H.J.; Ramaswamy, S.; Al-Dajani, W.W.; Tschirner, U., Process modeling and analysis of pulp mill-based integrated biorefinery with hemicellulose pre-extraction for ethanol production: A comparative study, Bioresource Technology, v.101, p.624-631, 2010.

Magaton, A.S.; Oliveira, R.; Lopes, O.R.; Milagres, F.R. ; Piló-Veloso, D.; Colodette, J.L., Composição Química da Madeira de Espécies de Eucalipto, $29^{a}$ Reunião Anual da Sociedade Brasileira de Química, 2006.

Mendes, C.V.T.; Carvalho, M.G.V.S.; Baptista, C.M.S.G.; Rocha, J.M.S.; Soares, B.I.G., Souza, G.D.A., Valorisation of hardwood hemicelluloses in the kraft pulping process by using an integrated biorefinery concept, Food and Bioproducts Processing, v. 87, p. 197-207, 2009.

Miller, G. L., Use of dinitrosalicilic acid reagent for determination of reducing sugar, Analytical Biochemistry, New York, v. 31, p. 426-428, 1959.

Sluiter, A.; Hames, B.; Ruiz, R.; Scarlata, C.; Sluiter J.; Templeton, D., Determination of Sugars, Byproducts, and Degradation Products in Liquid Fraction Process Samples, NREL Technical Report: NREL/TP-510-42623, 2006.

Sluiter, A.; Hames, B.; Ruiz, R.; Scarlata, C.; Sluiter J.; Templeton, D.; Crocker, D., Determination of Structural Carbohydrates and Lignin in Biomass, NREL Technical Report: NREL/TP-510-42618, 2008.

Vila, C.; Romero, J.; Francisco, J.L.; Garrote, G.; Parajó, J.C., Extracting value from Eucalyptus wood before kraft pulping: Effects of hemicelluloses solubilization on pulp properties, Bioresource Technology, v. 102, p. 5251-5254, 2011. 